\title{
Foreword: the third wave of entrepreneurship education and the importance of fun in learning
}

\author{
Jerome A. Katz
}

In my 2006 United States Association for Small Business and Entrepreneurship (USASBE) keynote address (Katz, 2006a), I made the point that the business-school based discipline of entrepreneurship was arguably the point of centrality for the new wave of growth in entrepreneurship education - a wave which is spreading out from business schools across campuses. The first wave of entrepreneurship education was a global one, spread by agricultural researchers through the model we have come to know as agricultural extension (Jones and Garforth, 1997; Katz, 2006b). The second wave came when the extension model was embraced by business school faculty and government business development specialists, and the business-school based approach to entrepreneurship education emerged, spreading across the United States, and then to business schools worldwide (Katz, 2006b).

Today, with business schools as the center or hub, we are seeing the third wave of growth, which is across individual campuses rather than jumping from one university to another. Called cross-campus entrepreneurship (Fountain, 2004; Shaver, 2005) or academic entrepreneurship (Shane, 2004), we see a renewed growth (cf. Vesper, 1985) across disciplines, and this volume showcases the nature and benefits of that third wave.

Part of this growth comes from the creation of new forms of entrepreneurship and academic programs to teach it. Part I of this volume focuses on this process. For example, in their chapters, David Kirby, Allan Gibb, Kevin Hindle, and Zelimir Todorovic conceptualize what forms that broader and more inclusive model of entrepreneurship might take. Why are new models needed? In part because of the burden of the intellectual legacy of business schools, with their fixation on the managerial (versus the entrepreneurial) model, which is wonderfully described in the chapter of Hjorth and Johannisson. It is also caused in part by the social legacy of business schools, with their fixation on perpetuating historical networks, networks which excluded women and minorities, a problem outlined and challenged in the chapter by Betters-Reed, Moore and Hunt in Part II. The potential for redefining the nature of entrepreneurship and entrepreneurship education comes from the power of groups to socially construct their realities. In her chapter in Part II, Denise Fletcher points out how moving away from the social constructivist model typical of business-school-based entrepreneurship education and toward a social constructionist approach could offer enhanced intellectual freedom to academics in search of a more realistic and inclusive paradigm.

This theme of a new paradigm of entrepreneurship education gets carried over into Part II of this volume. Part of maturity of a field is seen when there is general agreement on content, with continuing discussions on process. Through the lens of the new paradigm, even the traditional content becomes the subject of reflection and revision. Perhaps the sine qua non of the contemporary business-school approach to entrepreneurship is the business plan. Camille Carrier challenges the wisdom of propagating this model as 
entrepreneurship evolves in business schools and beyond, and champions alternative pedagogies in her chapter.

While small-business advising and consulting was pioneered by the agricultural extensionists of the nineteenth century (Katz, 2006b), it remains a mainstay of the business school approach, and as such is ripe for a reconsideration. The Robinson and Malach chapter provides an opportunity to observe the operationalization of one such broader approach, in the specific form of a multi-disciplinary entrepreneurship clinic. The agricultural extension heritage included evaluation as an essential element in the process of improvement, and that focus on outcomes has continued in the business school and seems to have made the move to the new paradigm of cross-campus entrepreneurship education. The chapter by Fayolle, Gailly and Lassas-Clerc in Part II describes one such effort at fresh thinking for evaluating a business-school program. It is complemented by a pair of studies in Part III that articulate and operationalize evaluative approaches based on the new paradigm of entrepreneurship education. Béchard and Grégoire use the idea of internal coherence to compare four widely different business programs, while Henry, Hill and Leitch use a more conventional approach to evaluate entrepreneurial training programs.

As noted, Part III complements the evaluative concept introduced in Part II of this volume, but also includes distinctive material on the specific content of entrepreneurship education. Hills, Hultman and Miles offer a review of the work and concepts which underlie a marketing approach to entrepreneurship. While unquestionably a part of the business school approach, marketing has historically taken a secondary position to management as a contributor and supporter of business-school entrepreneurship education. As the less-heard voice of the business-school based discipline (following the argument of Betters-Reed, Moore and Hunt in this volume), it is important to give attention to the contributions and alternatives offered in this unique chapter.

The remaining two chapters in Part III actually complement the ideas in Part I, in effect suggesting how to operationalize the kinds of thinking necessary to move away from the old paradigms of business-based, managerially driven, entrepreneurship education and to embrace a more distinctive, inclusive and realistic model. Francisco Liñán talks about how to increase the supply of entrepreneurially minded individuals in the university, as well as how these supply-enhancement efforts might be supported educationally. Paula Kyrö and Annukka Tapani approach the idea of increasing entrepreneurialism, but do so from the standpoint of teaching people how better to handle insecurity and manage risk.

In this first edition of the Handbook of Research in Entrepreneurship Education there is considerable promise, but it is promise which carries a measure of irony. Despite the promotion of a new paradigm, and efforts to ask tough questions which are intended to challenge basic assumptions, like Hindle's 'Can entrepreneurship be taught?' this is a volume of works by educators, individuals steeped in a profession whose fundamental tenet is positivist. If we could not make a difference in other people or institutions by our teaching, why would we do this work?

A generation ago, Argyris and Schon $(1974 ; 1978)$ demonstrated the difficulty of conducting what they called 'double-loop learning', learning which starts by challenging the fundamental beliefs and culture of an organization or profession. Argyris, ever the cynic and protagonist himself, admitted that double-loop learning was extraordinarily difficult to achieve, and often comes in momentary insights, not sustained bursts. He also admitted that being challenged by those from outside the dominant culture helped double-loop 
learning - the fable of the 'emperor's new clothes' often was mentioned in his classes as the metaphor.

The contributors here are making efforts to achieve the insights and benefits of doubleloop learning, and we can clearly see the benefits of their moments of double-loop learning insights. But it is also clear that there is still far to go. Consider, as you look at the biographical statements of the contributors, how many are based in business schools. If they can remain true to the dream of the new paradigm, contributions to the next edition of the Handbook will show a greater diversity of contributors and, with that, a greater chance of sustaining those moments of a double-loop learning perspective.

Those of you familiar with my work know that it is not characteristic of me to end on a note of negativism or even irony, and this Foreword is no exception. In these final words I want to draw your attention to a concept which recurs in a few of the chapters in this volume of the Handbook, which while by no means a common theme, is of great importance. It is the idea of fun in entrepreneurship.

Part of what this volume helped me recognize was the importance of fun. It is a subject I studied many years ago (Katz, 1987), and while I try to practice it in my teaching and work, I had not thought about it for years until reading this volume. Hindle infuses entrepreneurship education with Whitehead's vocational transcendence - the philosopher's polysyllabic expression for 'fun at work', and Allan Gibb talks about how entrepreneurship might be a way to help people draw enjoyment from an increasingly complex and uncertain world. When two thinkers of entrepreneurship who are from different generations and opposite corners of the world start talking about the same idea at the same time, I personally sit up and take notice. When we add to this how William Gartner implores our field to celebrate each other's contributions (Gartner, 2001), and the contributions of the entrepreneurs themselves (Carter et al., 2002), it brings me to the realization that fun should be a part of our approach to these other potential contributors to entrepreneurship across the campus.

Could fun have any practical value in the creation of a discipline or the process of educating individuals in it? The answer seems obvious - at least on the educating side. Students of all ages are attracted by the fun of a field, and that fun is part of what strengthens them to persevere when times are tough and not fun (Katz, 1987). How many students are attracted to chemistry by the initial chance to make something explode, burn or smell? It is fun like that which attracts and energizes young chemists to survive years of educational tedium. For those building a new discipline, often in institutionally hostile territory, the moments of fun may become all the more important as a way to sustain effort over the coming years.

In the old paradigm, with increasing numbers of courses in entrepreneurship majors, and high levels of consistency in what topics are taught and what techniques are used to teach, the potential for tedium in our own discipline increases. Professional schools promote professionalism, which seems to take a cultural position antithetical to the concept of fun. That is why MDs like 'Patch' Adams (who was portrayed on the screen by Robin Williams), get ostracized and remain the exception and not the rule in our professions (Adams and Mylander, 1993). Perhaps we need to make sure that part of the new paradigm of entrepreneurship education includes 'having fun' as one of its desiderata.

Can entrepreneurship education be fun? Arguably, our professional gatherings appear to be more fun than those of many other professions. Think of how many newcomers you 
have met at some convention of entrepreneurship educators who remarked how friendly these educators were, or how much fun they seemed to have together. Part of this comes from the current dominant culture of the discipline, which is more interested in sharing ideas than claiming them, which is benefiting from a time when entrepreneurship education (and the resources and students devoted to it) are growing rapidly, and which is perhaps inspired by the fun that the entrepreneurs we study encourage in themselves, their firms and, by extension, us.

Seeing a professor who recognizes and knows how to capture and share the fun and beauty of their discipline becomes a reminder to us all of what education at its best is all about. Watching a classic lecture by physicist Richard Feynman or hearing Guy Kawasaki (2004) talk about the fun inherent in recognizing The Art of the Start reminds us all of the awesome power of beauty and fun in our lives and in our teaching. ${ }^{1}$

It is a rare world which would have too much fun, and we are centuries from discovering one in the cosmos or creating one on this earth. However, we absolutely have the potential, the ability and (through efforts like this volume and the work you do every day) the material to bring moments of fun before our students, colleagues, and communities. Although we do not spend enough time or thought considering fun, whenever you can offer it to others, you make them, and our discipline, stronger.

So, welcome to the first volume of the first edition of the Handbook of Research in Entrepreneurship Education. Please remember to have some fun while you visit, and feel free to use the closing quote - after all, it was published in a respected handbook:

Done right, entrepreneurship should be fun, and done right, so should entrepreneurship education. (Jerome Katz)

\section{Note}

1. Those interested in videos showing Richard Feynman in action can find his filmography at www.imdb.com/ name/nm0275509/, and can see some of his lectures online at www.vega.org.uk/video/subseries/8. Those interested in Guy Kawasaki's presentations can go to http://edcorner.stanford.edu/AdvSearchServe3? $\mathrm{x}=$ $32 \& y=11 \&$ openkeyword $=\&$ authors $=24 \&$ eterms.

\section{References}

Adams, P. and Mylander, M. (1993), Gesundheit: Good Health Is a Laughing Matter, Rochester, VT: Healing Arts Press.

Argyris, C. and Schon, D.A. (1974), Theory in Practice: Increasing Professional Effectiveness, San Francisco, CA: Jossey-Bass.

Argyris, C. and Schon, D.A. (1978), Organizational Learning: A Theory of Action Perspective, San Francisco, CA: Jossey-Bass.

Carter, N.M., Gartner, W.B., Greene, P.G., Cox, L.W. and Reynolds, P.D. (2002), The Entrepreneur Next Door: Characteristics of Individuals Starting Companies in America, Kansas City, MO: Kauffman Foundation.

Fountain, M.W. (2004), 'The development and implementation of an inter-disciplinary graduate course linking engineering, medical, and business students with university research investigators to develop strategies to commercialize new technologies', ASEE Annual Conference and Exposition: Engineering Education Reaches New Heights, Salt Lake City, UT; USA, 20-23 June, http://services.bepress.com/cgi/viewcontent.cgi?article= $1016 \&$ context $=$ eci/teaching.

Gartner, W.B. (2001), 'Is there an elephant in entrepreneurship? Blind assumptions in theory development', Entrepreneurship Theory and Practice, 25 (4), 27-40.

Jones, G.E. and Garforth, C. (1997), 'The history, development, and future of agricultural extension', in B.E. Swanson, R.P. Bentz and A.J. Sofranko (eds), Improving Agricultural Extension. A Reference Manual, Rome: Food and Agriculture Organization of the United Nations, ch. 1, www.fao.org/docrep/W5830E/w5830e03. htm\#chapter $\% 201 \% 20 \% 20 \% 20$ the $\% 20$ history, $\% 20$ development, $\% 20$ and $\% 20$ future $\% 20$ of $\% 20$ agricultural $\%$ 20extension. 
Katz, J.A. (1987), 'Playing at innovation in the computer revolution', in M. Frese, E. Ulich and W. Dzida (eds), Psychological Issues of Human-Computer Interaction in the Work Place, Amsterdam: North-Holland, pp. 97-111.

Katz, J.A. (2006a), 'And another thing' (the 2006 Coleman Foundation White Paper on entrepreneurship), US Association for Small Business and Entrepreneurship, www.usasbe.org/data/documents/Katz $\% 20$ White $\% 20$ Paper-Final.pdf.

Katz, J.A. (2006b), 'Education and training in entrepreneurship', in J.R. Baum, M. Frese and R.A. Baron (eds), The Psychology of Entrepreneurship, Mahwah, NJ: Lawrence Erlbaum Associates.

Kawasaki, G. (2004), The Art of the Start, New York: Portfolio.

Shane, S.A. (2004), Academic Entrepreneurship: University Spinoffs and Wealth Creation, Cheltenham, UK and Northampton, MA, USA: Edward Elgar.

Shaver, K.G. (2005), 'Reflections on a new academic path: entrepreneurship in the arts and sciences', Peer Review, Spring, www.findarticles.com/p/articles/mi_qa4115/is_200504/ai_n14718124.

Vesper, K.H. (1985), Entrepreneurship Education - 1985, Babson, MA: Babson College Center for Entrepreneurial Studies. 
Jerome A. Katz - 9781847205377 